\title{
BASE TRANSIT TIME IN ABRUPT GaN/InGaN/GaN and AIGaN/GaN/AIGaN HBTs
}

\author{
Shean-Yih Chiu, A. F. M. Anwar and Shangli Wu \\ Electrical and Systems Engineering Department, University of Connecticut, CT 06269 \\ anwara@engr.uconn.edu
}

MRS Internet J. Nitride Semicond. Res. 4S1, G6.7 (1999)

\begin{abstract}
Base transit time, $\tau_{b}$, in abrupt npn GaN/InGaN/GaN and AlGaN/GaN/AlGaN double heterojunction bipolar transistors (DHBTs) is reported. Base transit time strongly depends not only on the quasi-neutral base width, but also on the low field electron mobility, $\mu_{n}$, in the neutral base region and the effective electron velocity, $S_{c}$, at the edge of base-collector heterojunction. $\mu_{n}$ and $S_{c}$ are temperature-dependent parameters. A unity gain cut-off frequency of $10.6 \mathrm{GHz}$ is obtained in $\mathrm{AlGaN} / \mathrm{GaN} / \mathrm{AlGaN}$ DHBTs and $19.1 \mathrm{GHz}$ in $\mathrm{GaN} / \mathrm{InGaN} / \mathrm{GaN}$ DHBTs for a neutral base width of $0.05 \mathrm{um}$. It is also shown that non-stationary transport is not required to study $\tau_{b}$ for neutral base width in the range of $0.05 \mathrm{um}$ for GaN-based HBTs.

\section{Introduction}

Wide bandgap group III-nitride semiconductors are currently being pursued for possible high temperature and high power applications. Current gain as high as $10^{5}$ is reported for $\mathrm{GaN} / \mathrm{SiC} \mathrm{HBT}$ [1]. In order to investigate high frequency performance the behavior of the base transit time, $\tau_{b}$, needs to be investigated. Mohammad et al. [2] has reported the dependence of $\tau_{b}$ on base doping concentration in a graded GaN/InGaN HBT.

The double integral formulation of $\tau_{b}$ by Kroemer [3] for HBTs is based upon the assumption that excess minority carrier concentration at the edge of base-collector depletion layer is negligible. Roulston [4] emphasized upon the use of a finite carrier velocity (saturation velocity) at the edge of the base-collector depletion region, thereby, introducing the component of base transit time due to velocity saturation. A more general formulation for carrier velocity at b-c heterojunction was used by Hafizi et al. [5]. Jahan et al. [6], based upon a self-consistent calculation of thermionic and tunneling components of the total current, proposed a tunneling factor for the determination of carrier velocity at the b-c junction. In this paper, the method formulated by Jahan et al. [7] is used in the determination of the effective electron velocity at base-collector junction which affects the electrons transport across base-collector junction.

In this paper, $\tau_{b}$ in abrupt GaN/InGaN/GaN and $\mathrm{AlGaN} / \mathrm{GaN} / \mathrm{AlGaN}$ HBT is reported. The computation of $\tau_{b}$ includes the effects of bandgap narrowing, carrier saturation and partitioning of the total current into thermionic and tunneling components. Results obtained from an ensemble Monte Carlo simulation are used in the determination of low field mobility, $\mu_{n}$.
\end{abstract}

\section{Theory}

Base transit time, $\tau_{b}$, can be expressed as a sum of $\tau_{b 1}+\tau_{b 2}$, where 


$$
\tau_{b 1}=\int_{0}^{W_{B}} \frac{n_{i b}^{2}(x)}{N_{A B}(x)} \int_{x}^{W_{B}} \frac{1}{D_{n}(y)} \frac{N_{A B}(y)}{n_{i b}^{2}(y)} d y d x
$$

and

$$
\tau_{b 2}=\frac{1}{S_{c}} \frac{N_{A B}\left(W_{B}\right)}{n_{i b}^{2}\left(W_{B}\right)} \int_{0}^{W_{B}} \frac{n_{i b}^{2}(x)}{N_{A B}(x)} d x
$$

where $N_{A B}(x)$ is the base doping concentration, $n_{i b}{ }^{2}(x)=n_{i e}{ }^{2} \exp \left(\Delta_{g} / k T\right)$ is the effective intrinsic carrier concentration in base region. The effective bandgap narrowing across the emitter-base heterojunction, $\Delta_{g}\left(\operatorname{In}_{x} G a_{1-x} N\right)=x \cdot E_{g}(\operatorname{InN})+(1-x) \cdot E_{g}(G a N)-x \cdot(1-x) E_{g b}$ $\left(\mathrm{E}_{\mathrm{gb}}=1.0 \mathrm{eV}\right)[8]$ where $\mathrm{x}$ is the In-mole fraction in $\operatorname{In}_{\mathrm{x}} \mathrm{Ga}_{1-\mathrm{x}} \mathrm{N}$ and $n_{i e}$ is the effective intrinsic carrier concentration in emitter region. $\tau_{b 1}$ is the component of the base transit time due to diffusion in the neutral base region and $\tau_{b 2}$ accounts for the finite base-collector junction velocity, $S_{c}$. The effective minority carrier velocity, $S_{c}$, characterizing electron transport across the space-charge region at the base-collector junction is formulated as $\mathrm{S}_{\mathrm{c}}$ $=v_{t h} \cdot \gamma \cdot \exp \left[\left(q v_{j p}-\Delta E_{c}\right) / k T\right]$ [9], where $\Delta E_{c}$ is the conduction band discontinuity, $v_{j p}$ is the applied voltage drop at the collector, $\gamma$ is the tunneling transmission factor, and $v_{t h}$ is the thermal velocity. The factor $\gamma$ is determined by invoking the proper partitioning of the total current into tunneling and thermionic components [7]. WKB method is used to compute the transmission probability required in calculating the tunneling component of the total current.

\section{Results and Discussions}

$5 \times 4 \mu \mathrm{m}^{2}$ single finger npn $\mathrm{GaN} / \mathrm{In}_{\mathrm{x}} \mathrm{Ga}_{1-\mathrm{x}} \mathrm{N}$ and $\mathrm{Al}_{0.2} \mathrm{Ga}_{0.8} \mathrm{~N}$ HBTs are investigated. The material parameters used in the simulation are as follows: $\mathrm{m}_{\mathrm{e}}(\mathrm{GaN})=0.2 \mathrm{~m}_{0}, \mathrm{~m}_{\mathrm{h}}(\mathrm{GaN})=0.6 \mathrm{~m}_{0}$ [10], $\mathrm{m}_{\mathrm{e}}(\mathrm{InN})=0.115 \mathrm{~m}_{0}$ [11], $\mathrm{m}_{\mathrm{h}}(\mathrm{InN})=1.6 \mathrm{~m}_{0}$ [12], $\mathrm{m}_{\mathrm{e}}(\mathrm{AlN})=0.314 \mathrm{~m}_{0}, \mathrm{~m}_{\mathrm{h}}(\mathrm{AlN})=0.71 \mathrm{~m}_{0}$ [13], $\mathrm{E}_{\mathrm{gGaN}}(\mathrm{T})=3.503+5.08 \times 10^{-4} \times \mathrm{T}^{2} /(\mathrm{T}-996) \mathrm{eV}, \quad \mathrm{E}_{\mathrm{gInN}}(\mathrm{T})=2.01-1.8 \times 10^{-4} \times \mathrm{T} \mathrm{eV}, \mathrm{E}_{\mathrm{gAlN}}(\mathrm{T})=6.118-$ $1.799 \times 10^{-3} \mathrm{~T}^{2} /(\mathrm{T}+1462) \mathrm{eV}[14], \quad \varepsilon_{\mathrm{GaN}}=9.5 \varepsilon_{0}, \quad \varepsilon_{\mathrm{InN}}=19.6 \varepsilon_{0}$ and $\varepsilon_{\mathrm{AlN}}=8.5 \varepsilon_{0}$ [13] where $\varepsilon$ is static dielectric constant, $m_{0}$ is electron rest mass, $T$ is absolute temperature $(K)$, and $\varepsilon_{0}$ is permittivity in vacuum. Emitter and collector doping concentrations equal $5 \times 10^{17} \mathrm{~cm}^{-3}$. The base is $0.05 \mathrm{um}$ wide and is doped uniformly $10^{19} \mathrm{~cm}^{-3}$. The conduction band offset, $\Delta \mathrm{E}_{\mathrm{c}}$, is assumed to be $75 \%$ of the difference in bandgaps of the constituting semiconductor alloys [15].

In Fig. 1(a) the low field mobility, $\mu_{n}$, and the diffusion coefficient, $D_{n}$, are plotted as a function of temperature for $\operatorname{In}_{0.2} \mathrm{Ga}_{0.8} \mathrm{~N}$ and $\mathrm{GaN}$ at a doping concentration of $10^{19} \mathrm{~cm}^{-3}$. The low field mobility data is obtained from an ensemble Monte Carlo simulation which accounts for piezoelectric, ionized impurity, alloy, intervalley, acoustic and polar optical phonon scattering [16]. The diffusion constant $D_{n}=k T / q \cdot \mu_{n} \cdot\left[F_{1 / 2}\left(\varsigma_{n}\right) / F_{-1 / 2}\left(\varsigma_{n}\right)\right] \quad$ where $\varsigma_{n}=\left(E_{f n}-E_{c}\right) / k T$ is the reduced Fermi level for electrons and $F_{ \pm 1 / 2}\left(\zeta_{n}\right)$ is the Fermi-Dirac integral. $D_{n}$ initially increases followed by gradual decrease beyond T=200K. In Fig. 1(b) the base-collector electron junction velocity, $\mathrm{S}_{\mathrm{c}}$, is plotted as a function of base-collector bias, $\mathrm{V}_{\mathrm{bc}}$, for varying In-mole fraction with temperature as a parameter. Due to a smaller band offset at the b-c junction $S_{c}$ approaches thermal velocity at lower $V_{b c}$ for $x=0.1$ as compared to that at $x=0.2$. The behavior of $S_{c}$ for $A l G a N / G a N / A l G a N$ is similar to that of $\mathrm{GaN} / \mathrm{InGaN} / \mathrm{GaN}$. 


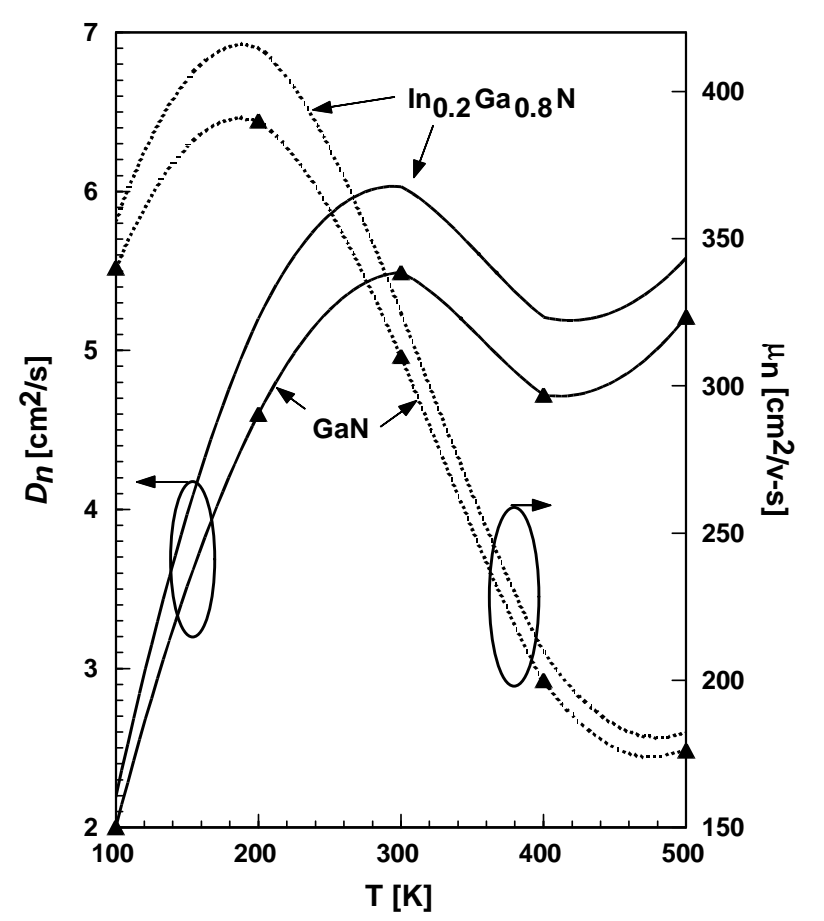

Fig. 1(a) Low field mobility $\mu_{n}$ and diffusion coefficient $\mathrm{D}_{\mathrm{n}}$ for $\mathrm{In}_{0.2} \mathrm{Ga}_{0.8} \mathrm{~N}$ and $\mathrm{GaN}$ as a function of temperature at a doping concentration of $10^{19} \mathrm{~cm}^{-3}$. Solid triangles represent $\mathrm{D}_{\mathrm{n}}$ and $\mu_{n}$ for $\mathrm{GaN}$.

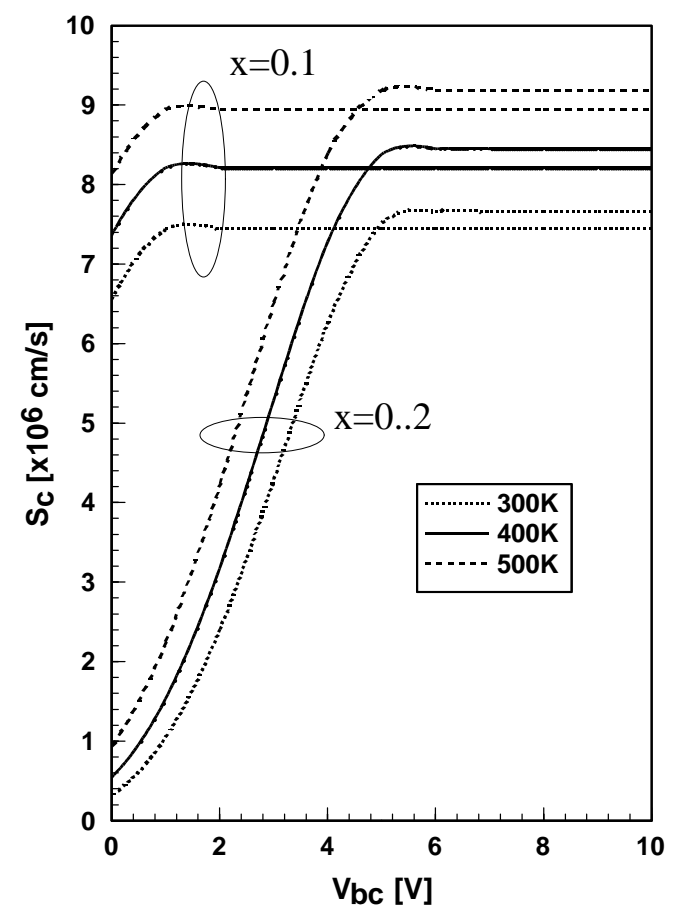

Fig. 1(b) The effective electron velocity at base-collector junction, $S_{c}$, versus $V_{b c}$ for $\mathrm{In}_{\mathrm{x}} \mathrm{Ga}_{1-\mathrm{x}} \mathrm{N} / \mathrm{GaN}$.

In Fig. 2(a) the base transit time $\tau_{b}$ is plotted as a function of $V_{b e}$ for $V_{b c}=3.0 V$. $\tau_{b}$ decreases with increasing In-mole fraction in $\mathrm{GaN} / \mathrm{In}_{\mathrm{x}} \mathrm{Ga} \mathrm{a}_{1-\mathrm{x}} \mathrm{N} / \mathrm{GaN}$ HBTs, irrespective of temperature and this behavior can be explained with the aid of Fig. 1. A higher $\mathrm{S}_{\mathrm{C}}$ at $\mathrm{x}=0.1$ results in a lower $\tau_{\mathrm{b} 2}$ as compared to that at $\mathrm{x}=0.2$ for $\mathrm{V}_{\mathrm{bc}}=3 \mathrm{~V}$. The magnitude of $\tau_{\mathrm{b} 1}$ at $\mathrm{x}=0.1$ is slightly greater than that at $x=0.2$. This may be attributed to a slightly higher low field mobility at $x=0.1$ that results in a lower diffusion constant as compared to that at $x=0.2$. The relative magnitudes of $\tau_{\mathrm{b} 1}$ and $\tau_{\mathrm{b} 2}$ reflects the role of the transport processes namely drift-diffusion versus thermionic field emission. As seen from Fig 2(b), the diffusion controlled component of the base transit time $\tau_{\mathrm{b} 1}$ is always the dominating time constant at elevated temperatures. However, at higher $D_{n}$ at $300 \mathrm{~K}$ results in a lower $\tau_{\mathrm{b} 1}$ and a higher $\tau_{\mathrm{b} 2}$. Or in other words, at $300 \mathrm{~K}$ the contribution of thermionic field emission related component of the base transit time $\tau_{\mathrm{b} 2}$ becomes significant. $\tau_{\mathrm{b}}$ for $\mathrm{Al}_{2 .} \mathrm{Ga}_{8} \mathrm{~N} / \mathrm{GaN}$ HBTs at $\mathrm{V}_{\mathrm{bc}}=3.0 \mathrm{~V}$ is controlled by $\tau_{\mathrm{b} 2}$ and is due to the small electron effective velocity. 


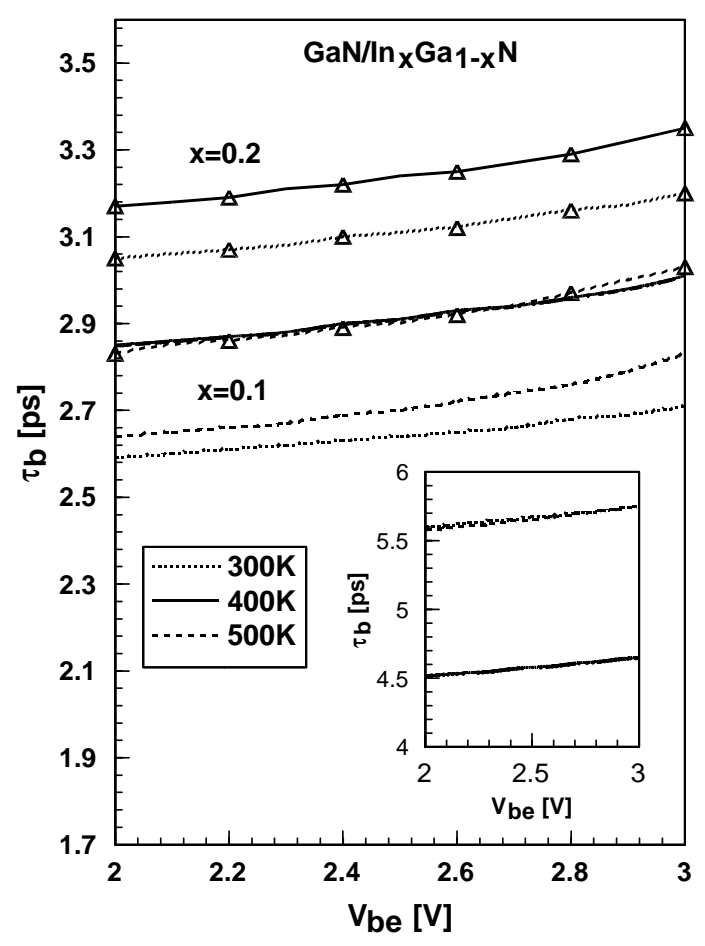

Fig. 2(a) $\tau_{b}$ is plotted as a function of $V_{b e}$ at various temperature for $\mathrm{GaN} / \mathrm{In}_{\mathrm{x}} \mathrm{Ga}_{1-\mathrm{x}} \mathrm{N}$ HBTs with base doping concentration of $10^{19}$ $\mathrm{cm}^{-3}, \mathrm{~V}_{\mathrm{bc}}=3 \mathrm{~V}$. Base width equals $0.05 \mathrm{um}$. The inset shows $\tau_{b}$ for $\mathrm{Al}_{0.2} \mathrm{Ga}_{0.8} \mathrm{~N} / \mathrm{GaN}$ DHBT. Lines represent $\mathrm{x}=0.1$ and lines with open triangles represent $x=0.2$.

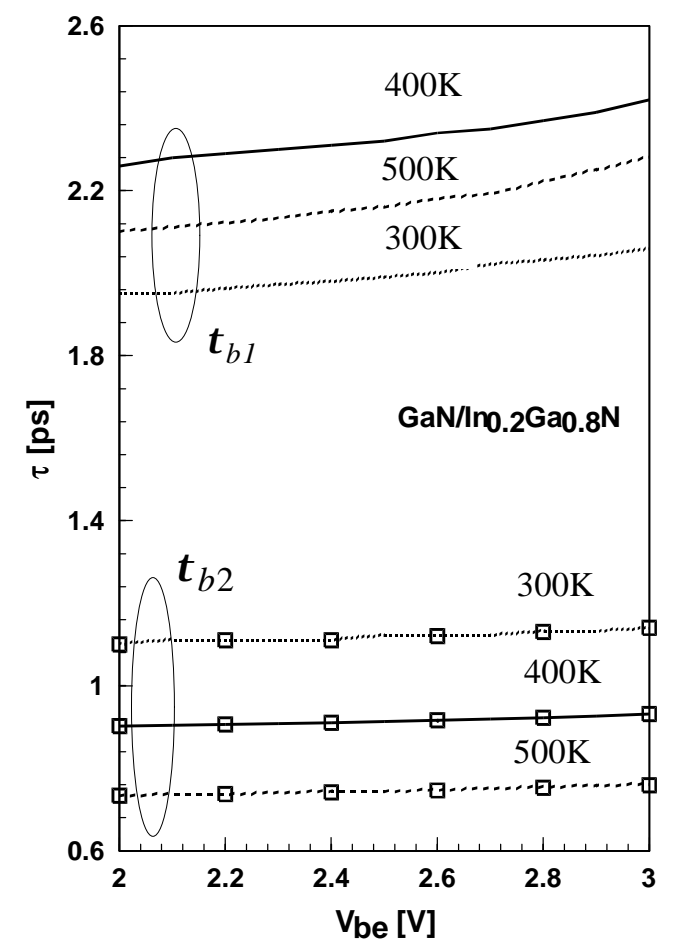

Fig. 2(b) Shows $\tau_{b 1}$ and $\tau_{b 2}$ for $\mathrm{GaN} / \mathrm{In}_{0.2} \mathrm{Ga}_{0.8} \mathrm{~N}$ DHBT. Lines represent $\tau_{b 1}$ and lines with open squares represent $\tau_{b 2}$.

The dependence of $\tau_{b}$ upon base width for a base doping concentration of $10^{19} \mathrm{~cm}^{-3}$ at room temperature is shown in Fig. $3 . \mathrm{V}_{\mathrm{be}}=2 \mathrm{~V}$ and $\mathrm{V}_{\mathrm{bc}}=3 \mathrm{~V}$ are assumed. As expected, $\tau_{b}$ increases with increasing base width. For extremely narrow base widths, the dominant component of $\tau_{b}$ is $\tau_{\mathrm{b} 2}$. As compared to $\mathrm{In}_{\mathrm{x}} \mathrm{Ga}_{1-\mathrm{x}} \mathrm{N}$-based HBTs, GaN-based HBTs have higher $\tau_{b}$ due to lower low field mobility and lower effective electron velocity at base-collector junction. The above calculation is performed using stationary transport. The validity of the above approximation is shown in Fig. 4, where the average velocity is plotted as a function of distance. As noted, the average velocity remains constant over a base width variation from $0.02 \mu \mathrm{m}$ to $0.8 \mu \mathrm{m}$ for both $\mathrm{GaN}$ and $\mathrm{In}_{2} \mathrm{Ga}_{8} \mathrm{~N}$ in the presence of an applied field of $500 \mathrm{KV} / \mathrm{cm}$. For comparison a similar plot for GaAs is also shown where the applied electric field is $10 \mathrm{KV} / \mathrm{cm}$. For GaAs the effect of non-stationary transport is clear and for base widths less than $1 \mu \mathrm{m}$ assuming stationary transport data becomes questionable.

In Fig. 5, the unity gain cutoff frequency $f_{T}=1 /\left(2 \cdot \pi \cdot \tau_{e c}\right)$ is plotted as a function of collector current density, $\mathrm{J}_{c}$, where $\tau_{e c}=\tau_{e}+\tau_{b}+\tau_{c}$ is the total transit time from emitter to the collector. $\tau_{e}$ is emitter charging time, expressed as $\tau_{e}=r_{e} \cdot C_{j e}$ where $r_{e}$ is the dynamic resistance and $C_{j e}$ is the base-emitter junction capacitance. $\tau_{c}=R_{c} \cdot C_{j c}$ is the collector 


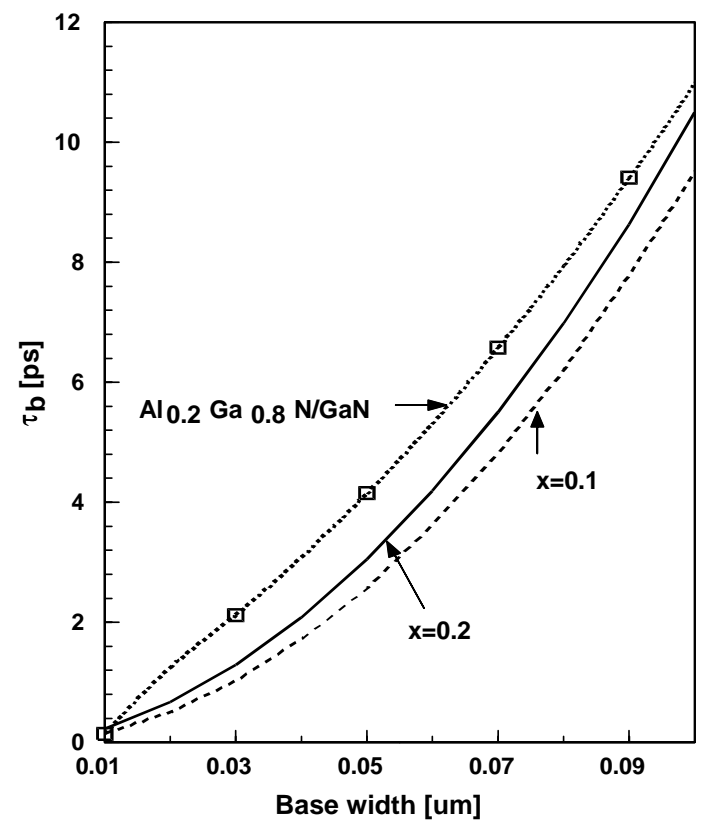

Fig. $3 \tau_{b}$ is plotted as a function of base width with In-mole fraction as a parameter for $\mathrm{GaN} / \mathrm{In}_{\mathrm{x}} \mathrm{Ga}_{1-\mathrm{x}} \mathrm{N}$ and $\mathrm{Al}_{0.2} \mathrm{Ga}_{0.8} \mathrm{~N} / \mathrm{GaN}$ HBTs (solid triangles). A base doping of $10^{19}$ $\mathrm{cm}^{-3}, \mathrm{~T}=300 \mathrm{~K}, \mathrm{~V}_{\mathrm{be}}=2.0 \mathrm{~V}$ and $\mathrm{V}_{\mathrm{bc}}=3.0 \mathrm{~V}$ are considered.

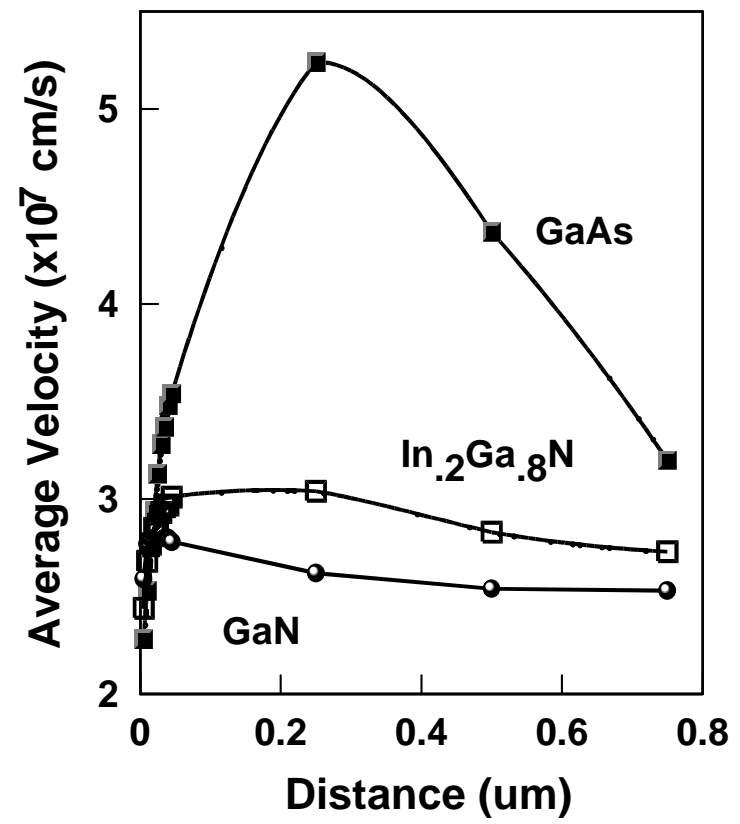

Fig.4 Average velocity is a function of distance at high electric field for GaAs, $\mathrm{GaN}$, and $\mathrm{In}_{0.2} \mathrm{Ga}_{0.8} \mathrm{~N}$.

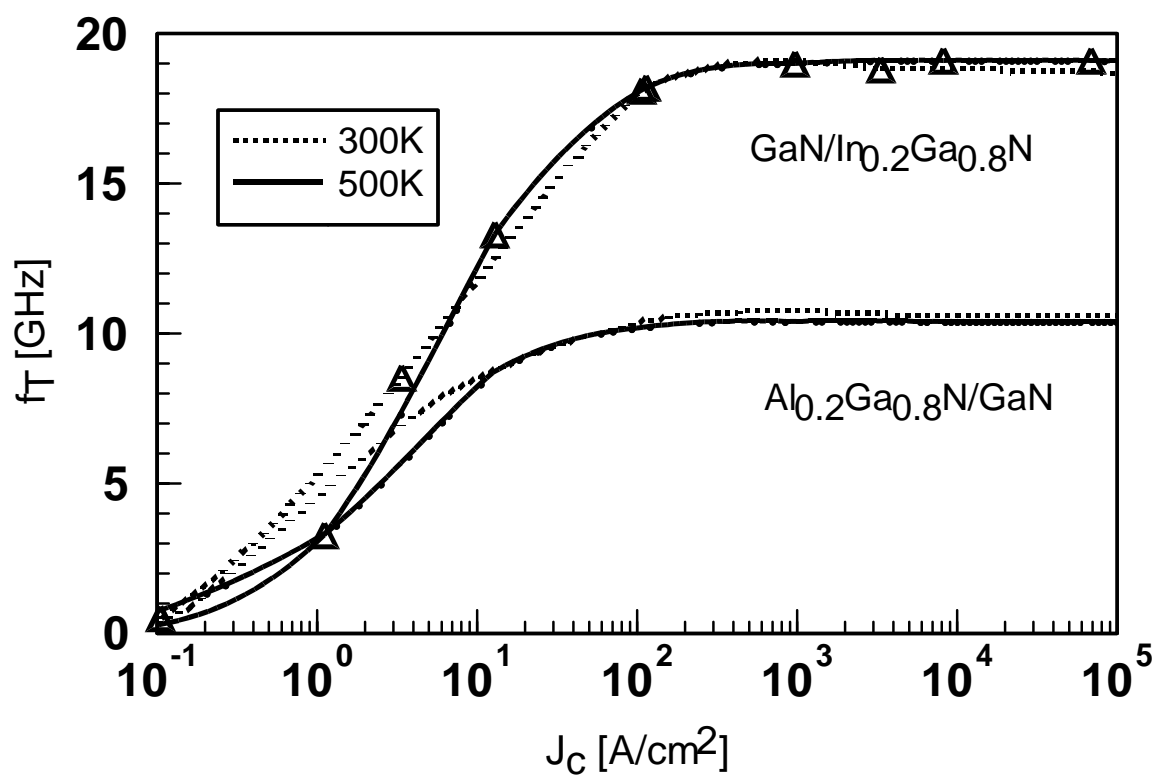

Fig. $5 f_{T}$ is shown as a function of collector current density at various temperatures for $\mathrm{GaN} / \mathrm{In}_{0.2} \mathrm{Ga}_{0.8} \mathrm{~N}$ and $\mathrm{Al}_{0.2} \mathrm{Ga}_{0.8} \mathrm{~N} / \mathrm{GaN}$ HBTs. Base width equals $0.05 \mathrm{um}$ with $\mathrm{N}_{\mathrm{AB}}=10^{19} \mathrm{~cm}^{-3}$. Solid lines represent $\mathrm{T}=500 \mathrm{~K}$ and dashed lines represent $\mathrm{T}=300 \mathrm{~K}$ 
charging time where $R_{c}$ is the collector resistance and $C_{j c}$ is the collector junction capacitance. For collector current densities below $100 \mathrm{~A} / \mathrm{cm}^{2} \tau_{\mathrm{e}}$ dominant time constant, however for current densities above $100 \mathrm{~A} / \mathrm{cm}^{2} \tau_{\mathrm{b}}$ dominates. An $f_{T}$ of $19.1 \mathrm{GHz}$ is obtained at $500 \mathrm{~K}$ for $\mathrm{GaN} / \mathrm{In}_{.2} \mathrm{Ga}_{8} \mathrm{~N} / \mathrm{GaN}$ DHBT. A higher low field mobility and b-c junction velocity in $\mathrm{Al}_{0.2} \mathrm{Ga}_{0.8} \mathrm{~N} / \mathrm{GaN}$ DHBT produce a $f_{T}$ of $10.6 \mathrm{GHz}$ at $300 \mathrm{~K}$.

\section{Conclusion}

Base transit time in abrupt $\mathrm{GaN} / \mathrm{InGaN} / \mathrm{GaN}$ and $\mathrm{AlGaN} / \mathrm{GaN} / \mathrm{AlGaN}$ HBTs are determined by accounting for bandgap narrowing, carrier degeneracy and the proper low field mobility. A narrow base width with a consequently large base resistance is recommended along with a lower In-mole fraction to realize superior unity gain current cut-off frequency, $f_{T}$. $f_{T}=10.6 \mathrm{GHz}$ at $\mathrm{T}=500 \mathrm{~K}$ for $\mathrm{Al}_{0.2} \mathrm{Ga}_{0.8} \mathrm{~N} / \mathrm{GaN} \mathrm{HBT}$ and $f_{T}=19.1 \mathrm{GHz}$ at $\mathrm{T}=300 \mathrm{~K}$ for $\mathrm{GaN} / \mathrm{In}_{0.2} \mathrm{Ga}_{0.8} \mathrm{~N}$ have been demonstrated.

\section{References}

[1] J. Pankove, S. S. Chang, H. C. Lee and R. J. Molnar, TEDM, 389 (1994)

[2] S. N. Mohammad and H. Morkoc, J. Appl. Phys., 78, 4200 (1995)

[3] H. Kroemer, Solid-State Electron., 28, 1101 (1985)

[4] D. J. Roulston, IEEE Electron Device Lett., 11, 88 (1990)

[5] M. Hafizi, D. C. Streit, L. T. Tran, K. W. Kobayashi, D. K. Umemoto, A. K. Oki, and S. K. Wang, IEEE Electron Device Lett., 12, 581 (1991)

[6] M. M. Jahan and A. F. M. Anwar, Solid-State Electron., 39, 133 (1996)

[7] M. M. Jahan and A. F. M. Anwar, Solid-State Electron., 39, 941 (1996)

[8] Y. Koida, H. Itoh, M. R. H. Khan, K. Hiramatsu, N. Sawaki, and I. Akasaki, J. Appl. Phys. 61, 4540 (1987)

[9] C. D. Parikh and F. A. Lindholm, IEEE Trans. on Electron Devices, 39, 1303 (1992)

[10] M. A. Khan, R. A. Skogman, J. M. Van Hove. S. Krishanakutty, and R. M. Kolbas, Appl. Phys. Lett. 56, 1257 (1991)

[11] H. Morkoc, S. Strite, G. B. Gao, M. E. Lin, B. Sverdlov, and M. Burns, J. Appl. Phys. 76, 1363 (1994)

[12] D. W. Jenkins and J. D. Dow, Phys. Rev. B39, 3317 (1992)

[13] M. S. Shur and M. A. Khan, MRS Bulletin. 44, 1997

[14] A. Dmitriev and A. Oruzheinikov, Internat. Symp. on Blue Lasser and Light Emitting Diodes, 360 (1996)

[15] Richard T. Webster and A. F. M. Anwar, MRS, Symp. Proc., 482, 929, Boston, 1997

[16] S. Wu, Richard T. Webster and A. F. M. Anwar, Proc. 1997 International Semicond. Device Research Symp., 385, University of Virginia, 1997 